Military Technical College Kobry El-Kobbah, Cairo, Egypt

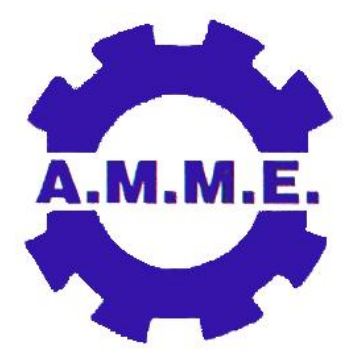

14th International Conference on Applied Mechanics and Mechanical Engineering.

\title{
Effect of hydroxy (HHO) gas addition on performance and exhaust emissions in compression ignition engines
}

By

\author{
Ali Can YILMAZ* Erinç ULUDAMAR * Kadir AYDIN *
}

\begin{abstract}
:
In this study, hydroxy gas (HHO) was produced by the electrolysis process of different electrolytes $\left(\mathrm{KOH}_{(\mathrm{aq})}, \mathrm{NaOH}_{(\mathrm{aq})}, \mathrm{NaCl}_{(\mathrm{aq})}\right)$ with various electrode designs in a leak proof plexiglass reactor (hydrogen generator). Hydroxy gas was used as a supplementary fuel in a four cylinder, four stroke, compression ignition engine without any modification and its effects on exhaust emissions and engine performance characteristics were investigated. The flow rate of hydroxy gas was measured by using various amounts of $\mathrm{KOH}, \mathrm{NaOH}, \mathrm{NaCl}$ (catalysts). These catalysts were added into the water to diminish hydrogen and oxygen bonds and $\mathrm{NaOH}$ was specified as the most appropriate catalyst. The experiments were performed at full open throttle operating conditions. Using hydroxy gas as a supplementary fuel in the engine resulted in reducing carbon monoxide (CO), hydrocarbon ( $\mathrm{HC}$ ) emissions and specific fuel consumption.
\end{abstract}

\section{Keywords:}


Hydrogen, hydroxy, enrichment, combustion, performance, emissions, electrolysis

* Çukurova University, Department of Mechanical Engineering, Adana

\section{Introduction:}

Faced with the ever increasing cost of conventional fossil fuels, researches worldwide are working overtime to cost-effectively improve internal combustion engine (ICE) fuel economy and emission characteristics. In recent years, many researchers have focused on the study of alternative fuels which benefit enhancing the engine economic and emissions characteristics. The main pollutants from the conventional hydrocarbon fuels are unburned/partially burned hydrocarbon $(\mathrm{UBHC})$, carbonmonoxide $(\mathrm{CO})$, oxides of nitrogen $\left(\mathrm{NO}_{\mathrm{x}}\right)$, smoke and particulate matter. It is very important to reduce exhaust emissions and to improve thermal efficiency. The higher thermal efficiency of diesel engines certainly has advantages for conserving energy and also solving the greenhouse problem. Among all fuels, hydrogen is a long term renewable, recyclable and non-polluting fuel. Hydrogen has some peculiar features compared to hydrocarbon fuels, the most significant being the absence of carbon. Very high burning velocity yields very rapid combustion and the wide flammability limit of hydrogen varies from an equivalence ratio $(\phi)$ of 0.1 to 7.1 , hence the engine can be operated with a wide range of air/fuel ratio. The properties of hydrogen are given in Table (1) [1]. Due to the low ignition energy and wide flammable range of hydrogen, hydrogen engines are quite suitable to run at lean conditions which are helpful for the enhanced engine economic and emissions performance [2,3]. Besides, compared with traditional fossil fuels, hydrogen is a carbonless fuel whose combustion doesn't generate emissions such as $\mathrm{HC}, \mathrm{CO}$ and $\mathrm{CO}_{2}$ [4]. The concept of using hydrogen as an alternative fuel for diesel engines is recent. The self ignition temperature of hydrogen is $858 \mathrm{~K}$, so hydrogen cannot be used directly in a $\mathrm{Cl}$ engine without a spark plug or glow plug. This makes hydrogen unsuitable as a sole fuel for diesel engines [5]. One alternative method is to use hydrogen in enrichment or induction, in which diesel is used as a pilot fuel for ignition. As hydrogen is a gas, it mixes well with air, resulting in complete combustion. Hydrogen-enriched engines produce approximately the same brake power and higher thermal efficiency than diesel engines over the entire range of operation $[6,7]$. 
There have been some investigations on hydrogen-enriched diesel combustion in $\mathrm{Cl}$ engines. Saravanan and Nagarajan [8] experimentally investigated the hydrogen-enriched air induction in a diesel engine system. The test results showed that an efficiency of $27.9 \%$ was achieved without knocking over the entire load range with $30 \%$ hydrogen enrichment. Also, they observed that specific fuel consumption decreased with increase in hydrogen percentage over the entire range of operation. Saravanan et al. [9] did an experimental investigation on hydrogen as a dual fuel for diesel engine system with exhaust gas recirculation technique. The test results demonstrated that the specific fuel consumption (SFC) decreased without EGR with $20 \mathrm{~L} / \mathrm{min}$ of hydrogen flow and they concluded that the reason for reduction in SFC is due to the operation of hydrogen fueled engine under lean burn conditions. Masood et al. [10] studied on experimental verification of computational combustion and emission analysis of hydrogen-diesel blends and the test results showed that the hydrogen-diesel co-fueling solved the drawback of lean operation of hydrocarbon fuels such as diesel, which were hard to ignite and resulted in reduced power output, by reducing misfires, improving emissions, performance and fuel economy. Saravanan and Nagarajan [11] studied on an experimental investigation on optimized manifold injection in a direct-injection diesel engine with various hydrogen flowrates. The test results showed that in the manifold injection technique, the optimized condition was the start of injection at gas exchange top dead centre (TDC) with an injection duration of $30^{\circ}$ crank angle (CA) with a hydrogen flowrate of $7.5 \mathrm{~L} / \mathrm{min}$. The brake thermal efficiency was found to increase by $9 \%$ compared with diesel fuel. $\mathrm{CO}$ emissions varied from 0.03 to $0.12 \mathrm{vol} \%$ compared with from 0.08 to $0.14 \mathrm{vol} \%$ in a diesel fuel investigation.

Researchers studied on hydrogen-enriched diesel engines. However, hydrogen has high auto-ignition temperature compared to diesel and this causes some challenges on operating a diesel engine just by increasing compression ratio. Therefore, a glow plug or a spark plug (external ignition sources) should be often used. Also hydrogen usage as a sole fuel in spark ignition engine brings some disadvantages to be overcome like backfire, preignition and knock. Therefore, hydrogen control in engine should be managed by electronic fuel injection systems. Since hydrogen has the fewest atomic mass (fewest molecular size), also storage is a major problem.

Table (1): Properties of hydrogen

\begin{tabular}{|l|c|c|c|}
\hline \multicolumn{1}{|c|}{ Properties } & Diesel & Unleaded gasoline & Hydrogen \\
\hline Autoignition Temperature (K) & 530 & $533-733$ & 858 \\
\hline Minimum ignition Energy (mJ) & - & 0.24 & 0.02 \\
\hline Flammability limits (volume \% in air) & $0.7-5$ & $1.4-7.6$ & $4-75$ \\
\hline Stoichiometric air-fuel ratio on mass basis & 14.5 & 14.6 & 34.3 \\
\hline Limits of flammability (equivalence ratio) & - & $0.7-3.8$ & $0.1-7.1$ \\
\hline Density at $16^{\circ} \mathrm{C}$ and 1.01 bar $\left(\mathrm{kg} / \mathrm{m}^{3}\right)$ & $833-881$ & $721-785$ & 0.0838 \\
\hline Net heating value $(\mathrm{MJ} / \mathrm{kg})$ & 42.5 & 43.9 & 119.93 \\
\hline Flame velocity $(\mathrm{cm} / \mathrm{s})$ & 30 & $37-43$ & $265-325$ \\
\hline Quenching gap in NTP air (cm) & - & 0.2 & 0.064 \\
\hline Diffusivity in air $\left(\mathrm{cm}^{2} / \mathrm{s}\right)$ & - & 0.08 & 0.63 \\
\hline Research octane number & 30 & $92-98$ & 130 \\
\hline Motor octane number & - & $80-90$ & - \\
\hline \hline
\end{tabular}


The aim of this experimental investigation was, to make a spectecular combination of anodes and cathodes in a simply adaptable ambient within the fuel system and to obtain an enhancement in combustion and reduction in exhaust emissions with electrolysis reaction without the need for storage tanks. In this experimental study, instead of pure hydrogen addition to diesel fuel, produced hydrogen gas along with oxygen (hydroxy gas, HHO, Brown's gas) were fed to the intake manifold of a direct injection $\mathrm{Cl}$ engine under various loads, which caused engine speed to decrease from $2800 \mathrm{rpm}$ to $1200 \mathrm{rpm}$. Hydroxy gas is in brown color and the form of unseperated hydrogen and oxygen generated by the electrolysis process of water $(\mathrm{NaOH}, \mathrm{KOH}$ or $\mathrm{NaCl}$ additives for more $\mathrm{HHO}$ production and optimum molality to keep electrical resistance-conductivity balance) by a unique electrode design. Hydrogen and oxygen did not form into $\mathrm{O}_{2}$ and $\mathrm{H}_{2}$ molecules. They were in their monoatomic state (a single atom per molecule). Water was split by electricity to form its various elements, oxygen and hydrogen. When Brown's gas (HHO) mixture was ignited, both explosion and implosion occured to form water, releasing the energy that was found in the bonds of the two elements in the form of heat. In the mono-atomic portion, there weren't any atomic bonds needed to be broken (the bonds of the $\mathrm{H}_{2}$ and $\mathrm{O}_{2}$ respectively) before turning back into water. The key difference of Brown's gas was the fact that some of the hydrogen and oxygen never go into a diatomic state. Hence, Brown's gas had more energy because these bonds were never made. In this state, which was an unstable state of $\mathrm{H}_{2} \mathrm{O}$ vapor, more energy was achieved compared to hydrogen burning with oxygen. Pulverized water clashed the fuel and they united. Water became the core and the fuel tended to be the water shell (due to density difference). During compression stroke, pressure and heat increased, the water exploded to steam and consequently, the fuel got atomized. After ignition, in-cylinder temperature increased rapidly which resulted water to be splitted into hydrogen and oxygen and reigniton occured which yielded increased combustion efficiency. Due to the oxgen atoms coming out with hydrogen (monoatomic structure), autoignition temperature of hydroxy was not as high as hydrogen (diatomic structure). Thus, hydroxy gas did not need an external ignition source like spark or glow plug and due to the simultaneous production and consumption of hydrogen, no storage was necessary, which resulted in safe operation [12]. Hydroxy gas was generated and used as a sole fuel in diesel engine to benefit from peculiar features and minimize disadvantages of hydrogen. It was observed that hydroxy system provided advantages in engine performance, emissions and specific fuel consumption at high engine speeds under lean conditions. At mid and low speeds, these specifications turned into disadvantages, due to minimum ignition energy of hydroxy which is a strongly decreasing function of equivalence ratio, preignition and knock occured. Also, low lean flammability limit of hydroxy resulted advantages only under dilute (lean) conditions.

\section{Experimental set-up and procedure:}

The hydroxy system was added to the engine without any modification. Hydroxy gas was generated in reactor container (plexiglass) by various types of electrodes (reactors) in various molality aqueous solutions of catalysts. The positive current positively charged the anodes which yielded the electrolysis reaction of the electrolytic solution and eventually released gaseous oxygen and hydrogen were generated which, in turn, surfaced at the top portion of reactor container. Electrical power that fed the electrodes were measured and it was observed that reaction field was the major factor that influenced the amount of hydroxy 
gas generated. Experiments on aqueous solutions of catalysts demonstrated that hydroxy gas flowrate increased in relation to mass fraction of catalyst in water. However, when the amount of catalyst reached $10 \%$ by mass, the $\mathrm{HHO}$ flowrate did not change. The plate electrode and $\mathrm{NaOH}_{(\mathrm{aq})}$ were found the most efficient reactors and catalysts in relation to electrical power consumed. Technical specifications of the engine used in this experimental study are shown in Table (2).

Table (2): Technical specifications of engine used in the experiments

\begin{tabular}{|l|l|}
\hline Configuration & In-line 4 \\
\hline Type & Direct injection diesel with glow plug \\
\hline Swept volume & $3567 \mathrm{~cm}^{3}$ \\
\hline Bore & $104 \mathrm{~mm}$ \\
\hline Stroke & $105 \mathrm{~mm}$ \\
\hline Oil cooler & Water-cooled \\
\hline Maximum torque & $255 \mathrm{Nm}$ at $1800 \mathrm{rpm}$ \\
\hline Maximum brake power & $80 \mathrm{~kW}$ at $3500 \mathrm{rpm}$ \\
\hline Recomended maximum speed & $3600 \mathrm{rpm}$ \\
\hline
\end{tabular}

Electrodes were made of $316 \mathrm{~L}$ stainless steel due to its high corrosion resistance. Every test was repeated three times and averages were taken as results. A multimeter was used to measure output voltage and current, a flowmeter was used to measure the flow rate of hydroxy gas and a gas analyzer was used to observe the exhaust emissions. Technical specifications of the system are given in Table (3).

Table (3): Technical specifications of the hydroxy system

\begin{tabular}{|l|l|}
\hline Maximum gas supply & $5 \mathrm{~L} / \mathrm{min}$ \\
\hline Electrodes (anode-cathode) & $316 \mathrm{~L}$ stainless steel plates \\
\hline Electrolysis voltage & $12 \mathrm{~V}$ \\
\hline Electrolysis current & $11 \mathrm{~A}$ \\
\hline Electrolyte & $\mathrm{NaOH}$ aqueous solution \\
\hline Reactor container volume & $8,5 \mathrm{~L}$ \\
\hline Water level control & $\mathrm{Float} \mathrm{system}$ \\
\hline Water temperature & $40-45^{\circ} \mathrm{C}$ \\
\hline Dimensions & $170 \times 400 \mathrm{~mm}$ (diameter $\times$ height) \\
\hline Weight & $3,5 \mathrm{~kg}$ \\
\hline
\end{tabular}

A float system was assembled into the reactor container to prevent short circuits through hydroxy gas expanded in reaction pot. Dynamometer which has a torque range of $0-1700$ $\mathrm{Nm}$, speed range of $0-7500 \mathrm{rpm}$ was connected with the engine to control the speed by automatically adjusting the load. The engine speed, power output, specific fuel consumption, $\mathrm{HC}$ and $\mathrm{CO}$ emissions were measured by the computer via a software. Hydroxy gas was firstly sent to a water safety system to prevent backflash using a $1 / 3$ water-filled pot before being sent to the intake manifold. Sensors were located on the container to observe excess growth of water temperature and gas pressure. A return-safety valve was used to prevent 
rising of gas pressure over 1 bar in the container. General view of experimental set-up is shown in Figure (1).

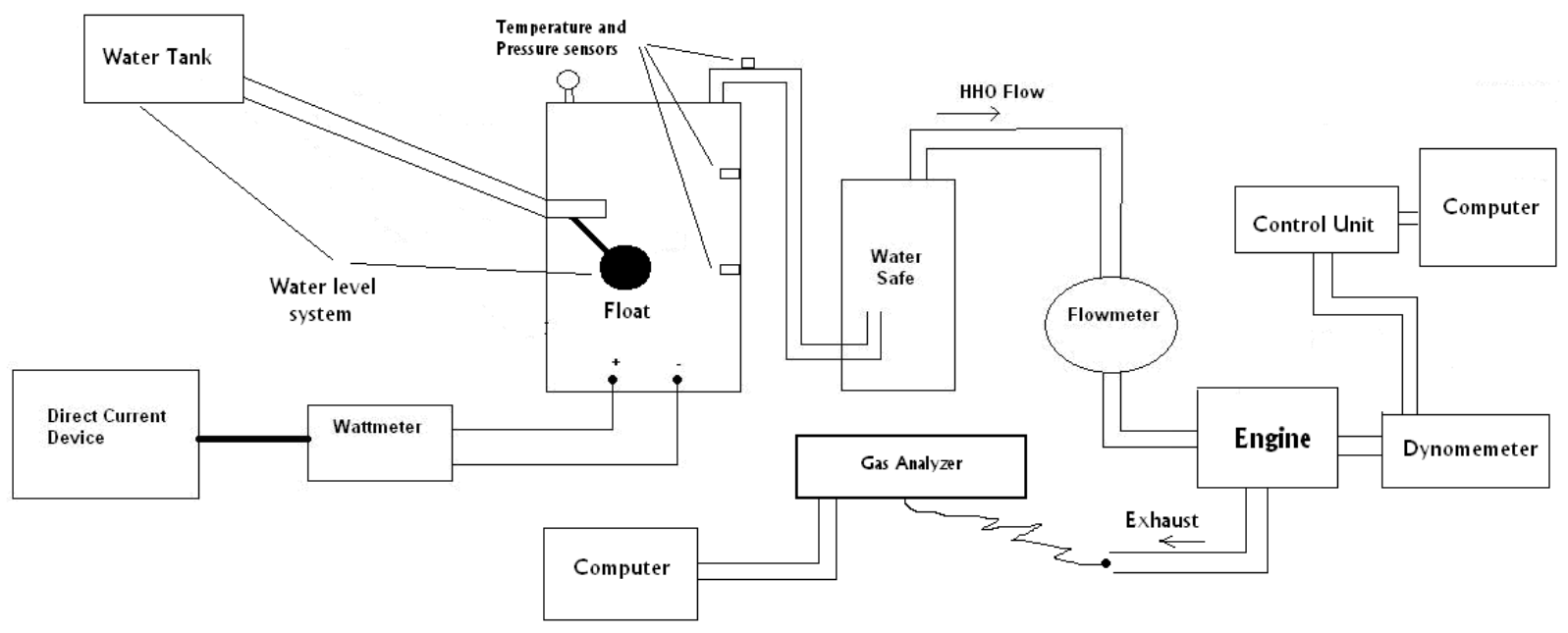

Figure (1): General view of experimental set-up

\section{Results and discussions:}

\subsection{Brake power:}

Figure (2) shows the variation of brake power with engine speed. An average increase of $20 \%$ at power is obtained during high speed conditions ( $\geq 1800 \mathrm{rpm})$. The increase in power is due to oxygen concentration of hydroxy gas and better mixing of hydroxy with air and fuel that yield enhanced combustion. Hydroxy gas diminishes the delay period of diesel combustion which in turn made the brake power increase. Also, high burning velocity of hydroxy yields much closer to ideal constant-volume combustion which results increased brake power. The results show that the addition of hydrogen can significantly enlarge the flammable region and extend the flammability limit to lower equivalence ratios. However, at low speeds $(\leq 1800 \mathrm{rpm})$, due to low lean-flammability limit of hydroxy gas, which allows stable combustion at highly dilute (lean) circumstances and mixture requirement at around stoichiometric (richer) conditions, hydroxy gas cannot have a positive effect on power output. Also, low auto-ignition temperature of hydroxy compared to diesel, which is a strongly decreasing function of equivalence ratio, may cause preignition and knock. At low engine speeds ( $\leq 1800 \mathrm{rpm}$ ), intake manifolds remain open longer compared to high speeds and that causes high volume occupation of hydroxy in the cylinders. Therefore, decreased volumetric efficiency which results reduced power output compared to neat diesel, is inevitable. 


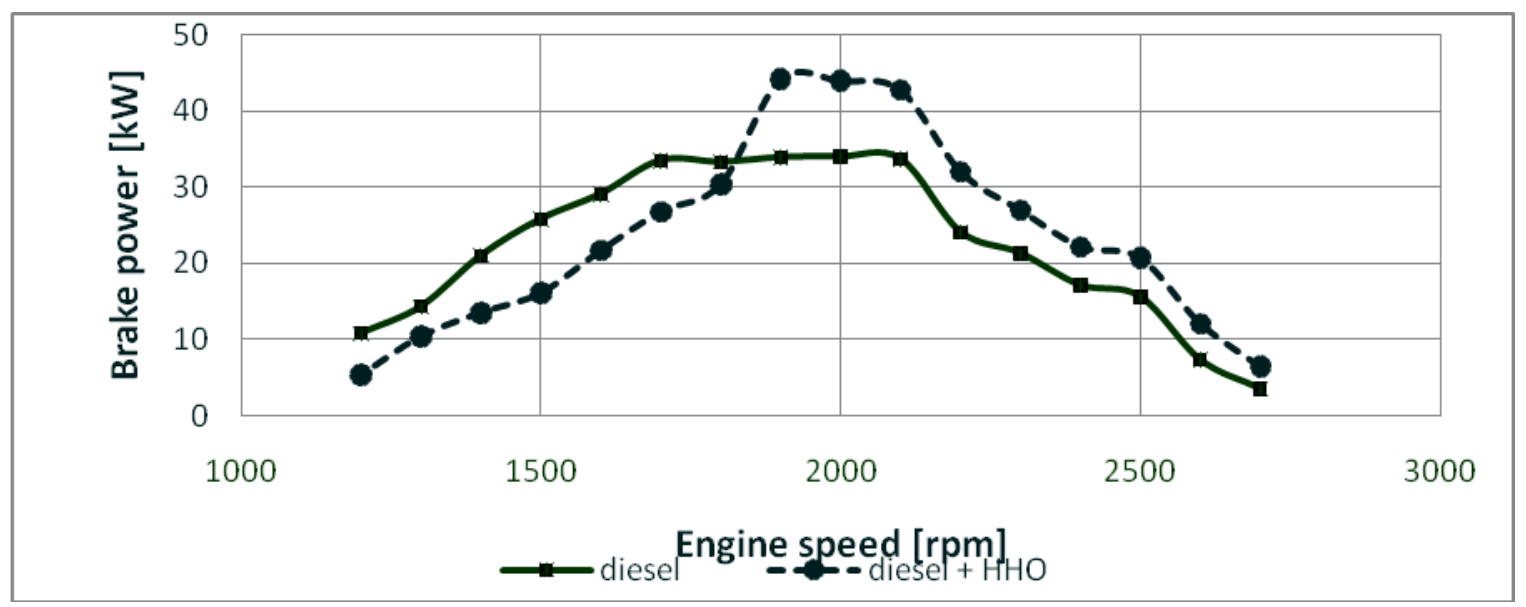

Figure (2): Variation of brake power with engine speed

\subsection{Specific fuel consumption:}

The variation of specific fuel consumption (SFC) with engine speed is shown in Figure (3). An average gain of $12,5 \%$ is achieved on SFC during high speed conditions ( $\geq 1800 \mathrm{rpm})$. The reduction in SFC is due to uniform mixing of hydroxy with air as well as oxygen index of hydroxy gas which assists diesel during combustion process and yields better combustion. However, at low speeds ( $\leq 1800 \mathrm{rpm}$ ), low lean flammability limit prevents hydroxy to have positive influence on combustion efficiency due to mixture requirement around stoichiometric conditions and high volume occupation of hydroxy causes reduced volumetric efficiency.

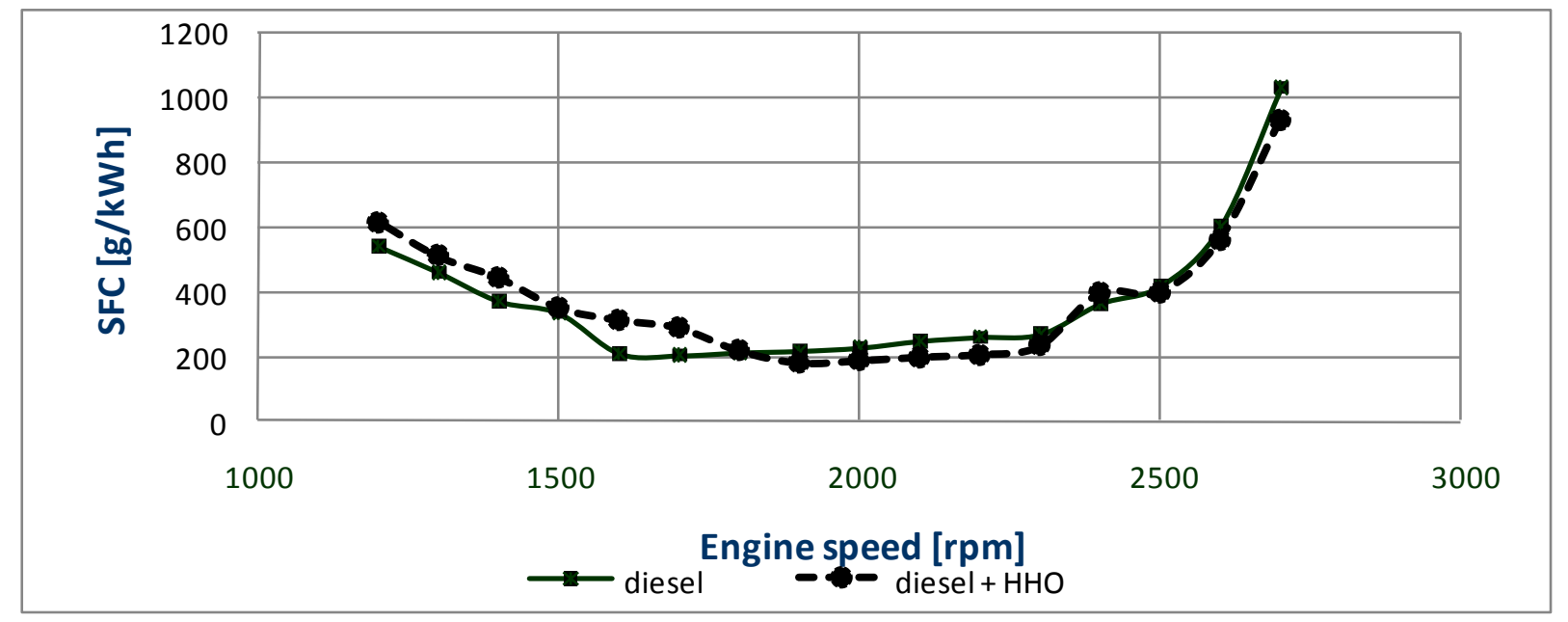

Figure (3): Variation of SFC with engine speed

\subsection{Hydrocarbon (HC) emission:}

The variation of $\mathrm{HC}$ emission with engine speed is depicted in Figure (4). A reduction of $27 \%$ at $\mathrm{HC}$ emission is achieved above the engine speed of $1800 \mathrm{rpm}$. High burning velocity which enhances the diesel burning, short quenching distance, wide flammability range and the absence of carbon in hydroxy result a major decrease in $\mathrm{HC}$ emission. Besides, oxygen index of hydroxy yields better combustion which diminishes $\mathrm{HC}$ emission. At low engine speeds, 
due to high volume occupation of hydroxy, correct air cannot be taken into the cylinders which prevents diesel to be combusted completely.

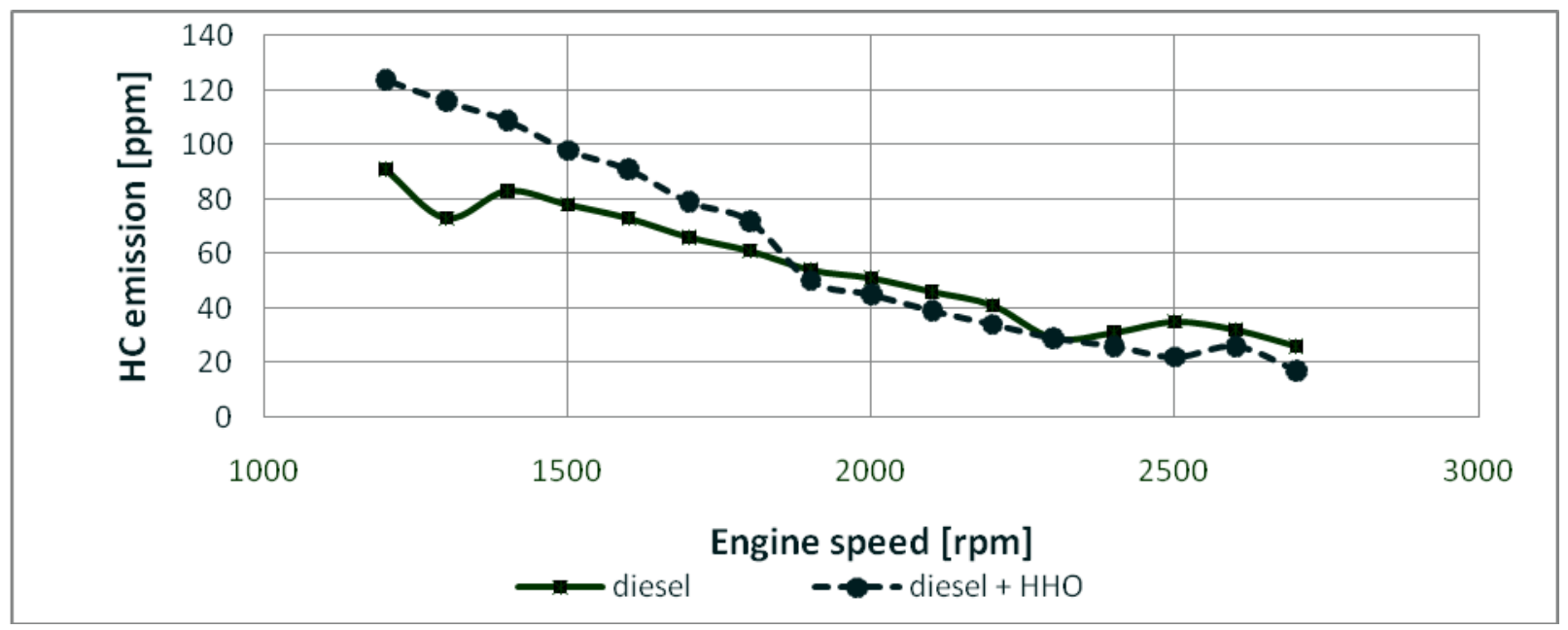

Figure (4): Variation of $\mathrm{HC}$ with engine speed

\subsection{Carbon monoxide (CO) emission:}

Figure (5) shows the variation of carbon monoxide emissions with engine speed. A reduction of $16 \%$ is gained at $\mathrm{CO}$ emissions at mid and higher engine speeds ( $\geq 1800 \mathrm{rpm})$. Absence of carbon in hydroxy gas is a major reason for $\mathrm{CO}$ reduction. Wide flammability range and high flame speed of hydroxy ensure engine to be operated at lean conditions at no load. Oxygen concentration reduces rapidly at high loads. However, since hydroxy gas contains oxygen, higher combustion efficiency is obtained and increase in $\mathrm{CO}$ emission is slower while approaching low speeds ( $\leq 1800 \mathrm{rpm})$.

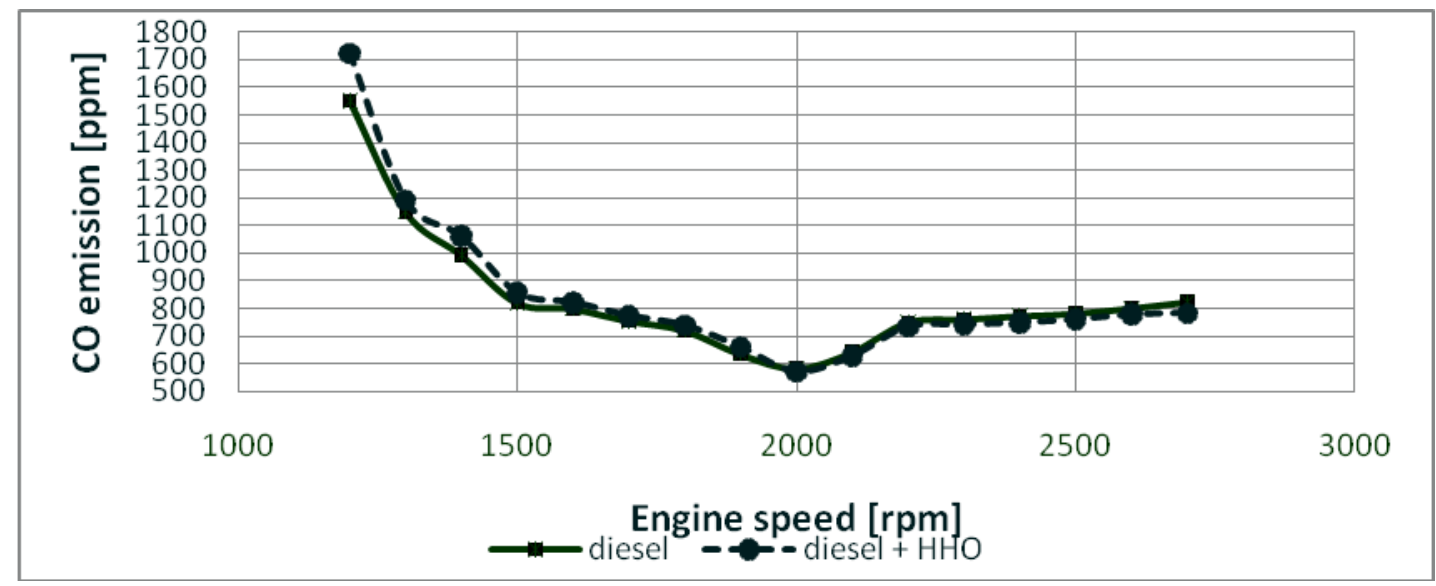

Figure (5): Variation of $\mathrm{CO}$ with engine speed

\section{Conclusions:}

In this paper, hydroxy gas a sole fuel to diesel and its effects on the combustion and emission characteristics of a direct injection compression ignition engine were investigated. The 
conclusions are listed as follows:

- High burning velocity and high energy content of hydroxy make diesel to ignite faster and result a reduction in ignition delay period and increased brake power. At low engine speeds, low lean-flammability limits of hydroxy causes challenges at higher equivalence ratios. Due to the long opening time of intake manifold at low speeds, high volume occupation (reduced volumetric efficiency) of $\mathrm{HHO}$ becomes inevitable. This can be minimized by an electronic control unit which adjusts the $\mathrm{HHO}$ amount by changing voltage or current in relation to engine speed (load). Since minimum ignition energy of hydroxy-air mixture is a decreasing function of equivalence ratio till stoichiometric (richer) conditions, power is reduced after hydroxy gas addition. The effect of hydroxy gas addition to obtain more power may be acquired with a sufficient capacity system at mid and higher speeds and leaner conditions.

- Uniform and improved mixing of hydroxy-air and oxygen content of hydroxy stimulate combustion which has a major effect on SFC by using an adequate capacity HHO system.

- High burning velocity, wide flammability range, oxygen content and absence of carbon make hydroxy gas an appropriate fuel addition to obtain a reputable reduction of $\mathrm{HC}$ and $\mathrm{CO}$ emissions when a sufficient hydroxy system is used at mid and higher speeds of engine and leaner conditions.

\section{References:}

[1] N. Saravanan, G. Nagarajan, C. Dhanasekaran and K. M. Kalaiselvan, Experimental Investigation of Hydrogen Port Fuel Injection in DI Diesel Engine, International Journal of Hydrogen Energy, Vol. 32, P. 4071-4080, 2007.

[2] T. D. Andrea, P. F. Henshaw and D. S. K. Ting, The Addition of Hydrogen to a Gasoline-fuelled SI Engine, International Journal of Hydrogen Energy, Vol. 29, P. 15411552, 2004.

[3] F. Ma and Y. Wang, Study on The Extension of Lean Operation Limit Through Hydrogen Enrichment in a Natural Gas Spark-Ignition Engine, International Journal of Hydrogen Energy, Vol. 33, P. 1416-1424, 2008.

[4] R. H. Ganeshb, V. Subramaniana, V. Balasubramanianb, J. M. Mallikarjuna, A. Ramesh and R. P. Sharma, Hydrogen Fueled Spark-Ignition Engine with Electronically Controlled Manifold Injection: An Experimental Study, Renewable Energy, Vol.33, P. 1324-1333, 2008.

[5] L. Barreto, A. Makihira and K. Riahi, The Hydrogen Economy in The 21st Century A Sustainable Development Scenario, International Journal of Hydrogen Energy, Vol. 28, P. 267-284, 2003.

[6] J. W. Buckel and S. Chandra, Hot Wire Ignition of Hydrogen-Oxygen Mixture, International Journal of Hydrogen Energy, Vol. 21, No. 1, P. 39-44, 1996.

[7] B. R. Haragopala, K. N. Shrivastava and H. N. Bhakta, Hydrogen For Dual Fuel Engine Operation, International Journal of Hydrogen Energy, Vol. 8, No. 5, P. 381-384, 1983. 
[8] N. Saravanan and G. Nagarajan, An Experimental Investigation of Hydrogen-Enriched Air Induction in a Diesel Engine System, International Journal of Hydrogen Energy, Vol. 33, P. 1769-1775, 2008.

[9] N. Saravanan, G. Nagarajan, K. M. Kalaiselvan and C. Dhanasekaran, An Experimental Investigation on Hydrogen as a Dual Fuel for Diesel Engine System with Exhaust Gas Recirculation Technique, Renewable Energy, Vol. 33, P. 422-427, 2008.

[10] M. Masood, M. M. Ishrat and A. S. Reddy, Computational Combustion and Emission Analysis of Hydrogen-Diesel Blends with Experimental Verification, International Journal of Hydrogen Energy, Vol. 32, P. 2539-2547, 2006.

[11] N. Saravanan and G. Nagarajan, An Experimental Investigation on Optimized Manifold Injection in a Direct-Injection Diesel Engine with Various Hydrogen Flowrates, Proceedings of the Institution of Mechanical Engineers, Part D: Journal of Automobile Engineering, Vol. 221, P. 1575-1584, 2007.

[12] Z. Dulger and K. R. Ozcelik, Fuel Economy Improvement by On-Board Electrolytic Hydrogen Production, International Journal of Hydrogen Energy, Vol. 25, P. 895-897, 2000. 